\title{
Tecnologia alternativa para produção de túberas-semente de inhame e seus reflexos na produtividade
}

\author{
Ademar P de Oliveira; Damiana F da Silva; Jandiê A da Silva; Arnaldo Nonato P de Oliveira; Rodolfo R \\ Santos; Natália V da Silva; Francisca Joseanny M e Oliveira \\ UFPB, C. Postal 02, 58397-000 Areia-PB; ademar@cca.ufpb.br
}

\section{RESUMO}

O trabalho teve como objetivo avaliar a produção de túberas-semente de inhame pelo sistema de plantio adensado de porções de túberas-semente e seus efeitos na produtividade. O trabalho foi conduzido na UFPB, em Areia (PB). Inicialmente, foram produzidas túberas-semente de inhame por meio do plantio de pedaços das mesmas com pesos de $25,50,75,100,125,150,175$ e 200 g, espaçados de $20 \times 20 \mathrm{~cm}$. As túberas-semente produzidas apresentaram pesos médias de 108, 133, 157, 181, 205, 229, 253 e $277 \mathrm{~g}$, as quais foram plantadas para avaliação da produtividade de túberas. O delineamento experimental foi de blocos casualizados com oito tratamentos e quatro repetições. Foram avaliados o peso médio e a produção de túberas-semente e as produtividades total e comercial. A produção e peso médio de túberas-semente aumentaram linearmente com o aumento do peso dos pedaços de túberas-semente plantados, com valores máximos de 277 e 4.170 g, respectivamente, obtidos com o pedaço de $200 \mathrm{~g}$ de túberas-semente. A produtividade média total foi de 13,6 $\mathrm{t} \mathrm{ha}^{-1}$, em função dos pesos de túberas-semente. A produtividade de túberas comerciais foi de $10,8 \mathrm{t} \mathrm{ha}^{-1}$, obtida com túberas-semente com peso médio de $181 \mathrm{~g}$, representando uma economia de $34 \%$ na quantidade de túberas-semente necessária para a implantação de um hectare do inhame.

Palavras-chave: Dioscorea cayennensis, túberas-semente, plantio adensado, produção de túberas.

\begin{abstract}
Alternative technology for yam tuber-seeds production and its reflexes in the tubers yield

This study was carried out in two steps at UFPB, in Areia, Paraiba state, Brazil, to evaluate the yam seed production by a high density planting system of tuber-seed portions and its effect on tuber yield. The experimental design in the two steps was randomized blocks with eight treatments and four replications. In the first step were produced yam tuber-seeds through planting of tuber-seed. Initially, we produced tuber-seed portions by planting pieces of 25, 50, 75, $100,125,150,175$ and $200 \mathrm{~g}$, spaced $20 \times 20 \mathrm{~cm}$. The seeds produced in the previous step, had average weight of 108, 133, 157, 181, 205, 229, 253 and $277 \mathrm{~g}$, which were planted to evaluate the yam yield. We evaluated the average mass and the production of seed tubers and the total and commercial yield. The production and average weight of tuber-seeds increased linearly with increasing weight of the pieces of tuber-seeds planted, with maximum values of 277 and $4,170 \mathrm{~g}$, respectively, obtained with a piece of $200 \mathrm{~g}$ of tuber-seeds. The total average yield was $13.6 \mathrm{tha}^{-1}$ depending on the weight of the planted seed-roots. The marketable yield of tubers was $10.8 \mathrm{tha}^{-1}$ obtained with tuber-seeds with an average weight of $181 \mathrm{~g}$, which represents a savings of $34 \%$ in the amount of tuber-seeds necessary for the implementation of a hectare of yam.
\end{abstract}

Keywords: Dioscorea cayennensis, tubers-seed, planting density, tubers production.

\section{(Recebido para publicação em 28 de dezembro de 2010; aceito em 16 de março de 2012) (Received on December 28, 2011; accepted on March 16, 2012)}

$\mathrm{O}$ inhame (Dioscorea cayennensis) alcança no Nordeste do Brasil grande importância socioeconômica, principalmente nos estados de Pernambuco e Paraíba, considerados os maiores produtores ao nível nacional. Essa espécie merece especial atenção por ser uma planta tropical, que poderá contribuir no suprimento da demanda reprimida de alimentos nas regiões em desenvolvimento e constituindo-se numa excelente fonte de minerais, carboidratos e de teores significativos de vitaminas B1, B2, A e C (Oliveira et al., 2002).

Apesar da importância que o inhame representa para o Brasil, especialmente para a Região Nordeste, nos últimos vinte anos vem se verificando acentuada redução da área plantada, de aproximadamente $40 \%$, acompanhado de redução de 23 a 56\% na produção e de 16 a 47\% nas exportações. Aponta-se como uma das causas, a baixa oferta de túberas-semente de boa qualidade e o elevado custo de sua aquisição (Santos et al., 2007). Este custo chega a $40 \%$ do custo de produção (Silva, 2002), uma vez que a sua produção se da pela colheita precoce, aos sete meses após o plantio (Santos \& Macêdo, 2002). Esse método tem custo elevado, porque necessita de mão-de-obra especializada (Oliveira et al., 2007).

Relatos de pesquisas têm demonstrado que é possível a produção de túberas-semente de melhor qualidade com custo mais baixo, substituindo-se o sistema tradicional pelo plantio adensado. Essa técnica poderá proporcionar uma redução significativa da quantidade de túberas-semente necessária para a implantação da lavoura, além de uniformizar a produção de plantas, uma vez que toda túbera-semente produzida terá grande quantidade de gemas de brotação (Santos, 2006).

$\mathrm{O}$ inhame pode ser propagado por túbera-semente inteira ou por porções da mesma. A túbera-semente inteira possui grande quantidade de gemas de brotação; consequentemente apresenta brotação mais rápida, e quando plantada possibilita uniformização da população 
de plantas em campo e aumento de produção de túberas comerciais (Silva, 2002). Silva et al. (2009), avaliando a produção pelo sistema de plantio adensado, obtiveram túberas-semente de boa qualidade, as quais proporcionaram maior produtividade comercial que a média nacional.

A quantidade de túberas-semente na implantação de um hectare de inhame é elevada, chegando até a $3.000 \mathrm{~kg}$, representando mais de $40 \%$ do volume de recursos empregados. Além disso, a produtividade do inhame está diretamente relacionada ao processo de seleção de túberas-semente, porque o tamanho e/ ou peso de suas porções se reveste da maior importância para a exploração racional da cultura (Silva et al., 2009).

A qualidade e o tamanho das túberas-semente são fatores responsáveis pela uniformidade e rapidez no estabelecimento de uma lavoura de inhame, exercendo papel fundamental no desenvolvimento da planta e favorecendo de forma significativa o rendimento da cultura (Santos, 1998). O ideal seria o uso de túbera-semente inteira com peso médio de $200 \mathrm{~g}$, a qual pode ser considerada de alta qualidade por permitir a uniformização da lavoura, ter um custo relativamente baixo e não apresentar a necessidade de cortá-la para o plantio (Silva et al., 2009). Conforme Santos (2006), a produção de túberas-semente com essas características é possível por meio do plantio de forma adensada de porções de túberas-semente com peso variando de 50 a $100 \mathrm{~g}$. Esta forma de plantio impede o crescimento normal do inhame, resultando na produção de pequenas túberas consideradas excelentes para a sua propagação, sem a necessidade de ser fracionada (Santos et al., 2007a).

Diante do exposto, objetivou-se com este trabalho avaliar a produção de túberas-semente de inhame pelo sistema de plantio adensado de porções de túberas-semente e sua relação com a produtividade de túberas.

\section{MATERIAL E MÉTODOS}

O trabalho foi conduzido em duas etapas (2007 e 2008), em condições de campo, na UFPB, localizado no município de Areia, Microrregião do Brejo Paraibano (6 $6^{\circ} 58^{\prime} \mathrm{S}, 35^{\circ} 42^{\prime} \mathrm{W}$, altitude de $575 \mathrm{~m}$ ). De acordo com a classificação bioclimática de Gaussem, o bioclima predominante na área é o $3 \mathrm{dth}$ nordestino sub-seco, com precipitação pluviométrica média anual em torno de 1.400 mm. Pela classificação de Köppen, o clima é do tipo As', que se caracteriza como quente e úmido, com chuvas de outono-inverno. A temperatura média anual oscila entre 23 a $24^{\circ} \mathrm{C}$ (Brasil, 1972). O solo da área experimental foi classificado pela Embrapa (2006) como Neossolo Regolítico Psamitico tipico textura franca, com as características químicas e físicas: $\mathrm{pH}\left(\mathrm{H}_{2} \mathrm{O}\right)=6,2 ; \mathrm{P}$ disponível $=11,4 \mathrm{mg} \mathrm{dm}^{-3} ; \mathrm{K}=46,00 \mathrm{mg}$ $\mathrm{dm}^{-3} ; \mathrm{Ca}^{+2}+\mathrm{Mg}^{+2}=2,8 \mathrm{cmol}_{\mathrm{c}} \mathrm{dm}^{-3} ; \mathrm{H}+$ Al trocável $=3,30 \mathrm{cmol}_{\mathrm{c}} \mathrm{dm}^{-3}$ e matéria orgânica $=17,2 \mathrm{~kg} \mathrm{dm}^{-3}$; areia $=841,50$ $\mathrm{g} \mathrm{kg}^{-1} ;$ silte $=88,00 \mathrm{~g} \mathrm{~kg}^{-1} ; \operatorname{argila}=70,50$ $\mathrm{g} \mathrm{kg}^{-1}$; densidade do solo $=1,37 \mathrm{~kg} \mathrm{dm}^{-3}$; densidade de partículas $=2,61 \mathrm{~g} \mathrm{dm}^{-3} \mathrm{e}$ porosidade total $=0,47 \mathrm{~m}^{3} \mathrm{~m}^{-3}$.

Inicialmente, túberas-semente sadias de inhame cultivar Da Costa foram seccionadas em porções com pesos de 25 , $50,75,100,125,150,175$ e $200 \mathrm{~g}$, as quais foram plantadas em canteiros com $2 \times 1 \mathrm{~m}$, sob espaçamento de $20 \times 20 \mathrm{~cm}$. A parcela experimental foi composta por 20 porções de túberas-sementes. $\mathrm{O}$ delineamento experimental utilizado foi de blocos casualizados, com oito tratamentos e quatro repetições.

Uma semana antes do plantio foram incorporados em cada canteiro 5 $\mathrm{kg} \mathrm{m}^{-2}$ de esterco bovino curtido. Após nove meses, as túberas-semente foram colhidas e transportadas para galpão para avaliação do peso médio e da produção. Após repouso fisiológico de 60 dias, as túberas-semente inteiras foram plantadas em campo. Para avaliação dos efeitos dos tratamentos em campo foi usado também o delineamento experimental em blocos casualizados com oito tratamentos, em quatro repetições, porém compostos pelos pesos de túberas-semente de 100, 125, 150, $175,200,225,250$ e 275 g, obtidas, respectivamente, a partir das porções utilizadas na primeira etapa $(25,50,75$, $100,125,150,175$ e $200 \mathrm{~g})$. A parcela foi composta por 20 plantas, todas con- sideradas úteis para efeito de avaliação.

O preparo do solo constou de uma aração seguida da confecção dos leirões e abertura de covas. Uma semana antes do plantio foram realizadas nas covas, adubações por meio do fornecimento de $15 \mathrm{t} \mathrm{ha}^{-1}$ de esterco bovino, $100 \mathrm{~kg} \mathrm{ha}^{-1} \mathrm{de}$ $\mathrm{P}_{2} \mathrm{O}_{5}$ e de $70 \mathrm{~kg} \mathrm{ha}^{-1}$ de $\mathrm{K}_{2} \mathrm{O}$, e aos 60 e 90 dias após o plantio foram fornecidos em adubação de cobertura $80 \mathrm{~kg} \mathrm{ha}^{-1}$ de $\mathrm{N}$ parcelado em partes iguais. Como fonte de $\mathrm{P}_{2} \mathrm{O}_{5} \mathrm{~N}$ e $\mathrm{K}_{2} \mathrm{O}$ foram empregados $\mathrm{O}$ superfosfato triplo, sulfato de amônio e cloreto de potássio, respectivamente.

O plantio das túberas-semente foi realizado manualmente, no espaçamento de $1,2 \times 0,6 \mathrm{~m}$, enterrado-as a $10 \mathrm{~cm}$ de profundidade do topo do leirão. Durante a condução do experimento, foram feitas capinas manuais com o auxílio de enxadas, visando manter a área livre de plantas daninhas. Por ocasião das capinas, foram realizadas também amontoas, com o objetivo de manter os leirões bem formados e proteger as túberas contra o efeito dos raios solares. $\mathrm{Na}$ ausência de precipitação, foram efetuadas irrigações pelo sistema de aspersão convencional, procurando manter o solo com disponibilidade de umidade suficiente para o desenvolvimento do inhame. Para a orientação do crescimento das plantas, foi adotado o sistema de tutoramento tradicional, com um tutor (vara), medindo aproximadamente 1,60 $\mathrm{m}$ de altura.

A colheita das túberas foi realizada aos noves meses após o plantio, por ocasião do secamento de aproximadamente 95\% dos ramos e folhas das plantas e encerramento do ciclo da cultura, com auxílio de enxadecos.

Foram avaliados o peso médio de túberas-semente, a produção de túberas-semente e as produtividades total e comercial de túberas. Foram consideradas túberas comerciais aquelas com peso superior a $700 \mathrm{~g}$ e inferior a $3.000 \mathrm{~g}$, cilíndrica e sem presença de nematóides (Silva, 2002). Os dados obtidos nas duas etapas foram submetidos à análise de variância, utilizando-se o teste $\mathrm{F}$ para comparação dos quadrados médios e as médias comparadas pelo teste Tukey, até $5 \%$ de probabilidade. Para os efeitos quantitativos foram realizadas análises de regressão polinomial, empregando-se o software SAEG (2000). 


\section{RESULTADOS E DISCUSSÃO}

O peso médio e a produção de túberas-semente aumentaram linearmente com o aumento dos pesos dos pedaços de túberas-semente inicialmente plantadas, com valores máximos de $277 \mathrm{~g}$ e $4.150 \mathrm{~kg} \mathrm{ha}^{-1}$, respectivamente, obtidos com pedaços de $200 \mathrm{~g}$ de túberas-semente (Figuras 1 e 2).

Embora o pedaço de $200 \mathrm{~g}$ de túberas-semente tenha resultado em maior peso médio e produção de túberas-semente, o pedaço de $120 \mathrm{~g}$ resultou na obtenção da túbera-semente com peso ideal para o plantio do inhame, definido por Santos (1998), que é de $200 \mathrm{~g}$. Túberas-semente grandes proporcionam maiores produções do que as pequenas (menores que $100 \mathrm{~g}$ ); no entanto, seu emprego é mais oneroso, notadamente pelo aumento da quantidade de túberas-semente utilizadas para implantação da lavoura (Santos, 2002).

A túbera-semente produzida no sistema avaliado pode ser considerada de excelente qualidade por atender à exigência do produtor, que busca sempre o plantio de túbera-semente inteira, a qual proporciona a uniformidade na população de plantas (Santos et al., 2009). A brotação desuniforme ocasiona perdas consideráveis aos produtores, devido à morte das túberas-semente devido a insetos e patógenos no solo e pelas intempéries que danificam as gemas de brotação (Oliveira, 2002). Nesse sentido, a implantação de tecnologia de produção de túberas-semente para o inhame pelo sistema de pedaços de túberas-semente, plantadas de forma adensada, poderá ser um aliado na redução de custos com a aquisição de túberas-semente e na elevação do rendimento do inhame.

A produtividade total de túberas não variou com os pesos das túberas-semente, sendo a média de 13,6 t ha $^{-1}$ (Figura 3); por outro lado, a produtividade comercial foi influenciada significativamente pelos pesos das túberas-semente, sendo que o plantio de túberas-semente com peso de 181 g possibilitou a obtenção da produtividade máxima de $10,9 \mathrm{t} \mathrm{ha}^{-1}$ de túberas comerciais. A produtividade comercial de túberas superou a média da produti-

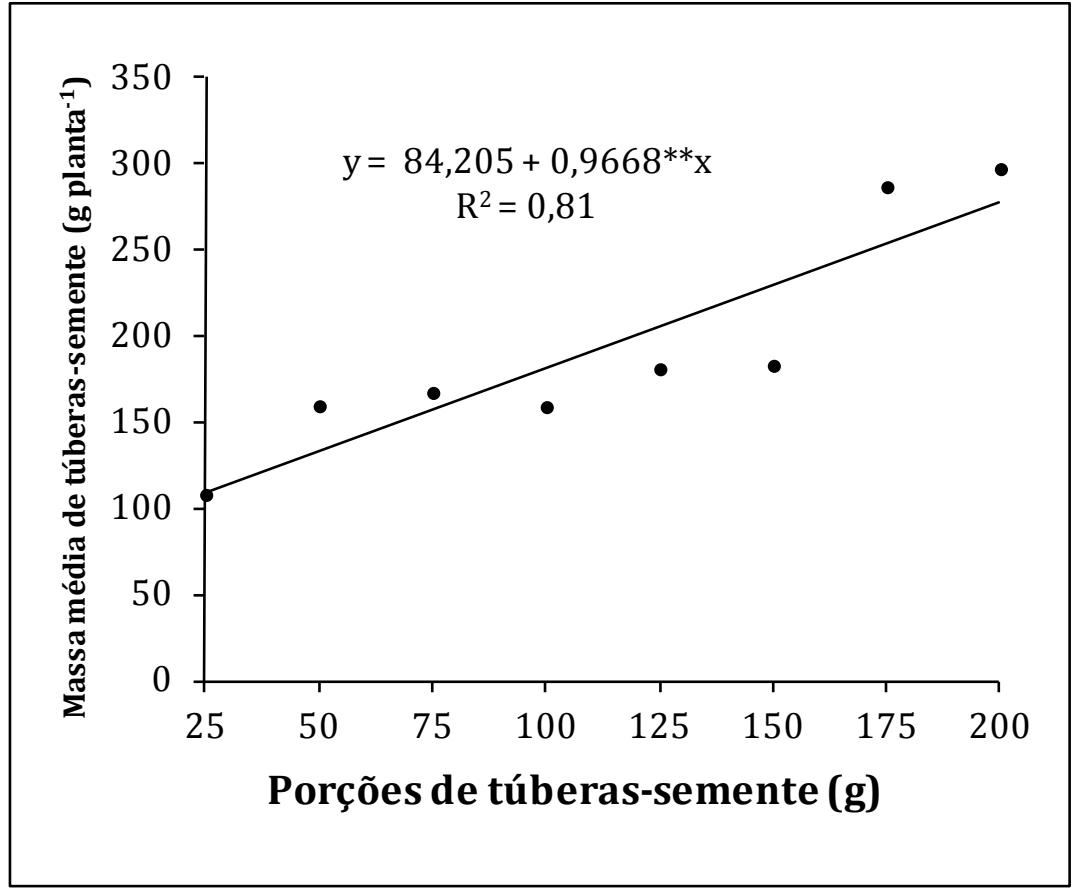

Figura 1. Peso médio de túberas-semente de inhame, colhidas de plantio adensado de pedaços de túberas-semente em 2,00 $\mathrm{m}^{2}$ (yam seeds average weight obtained through adensed planting). Areia, UFPB, 2009.

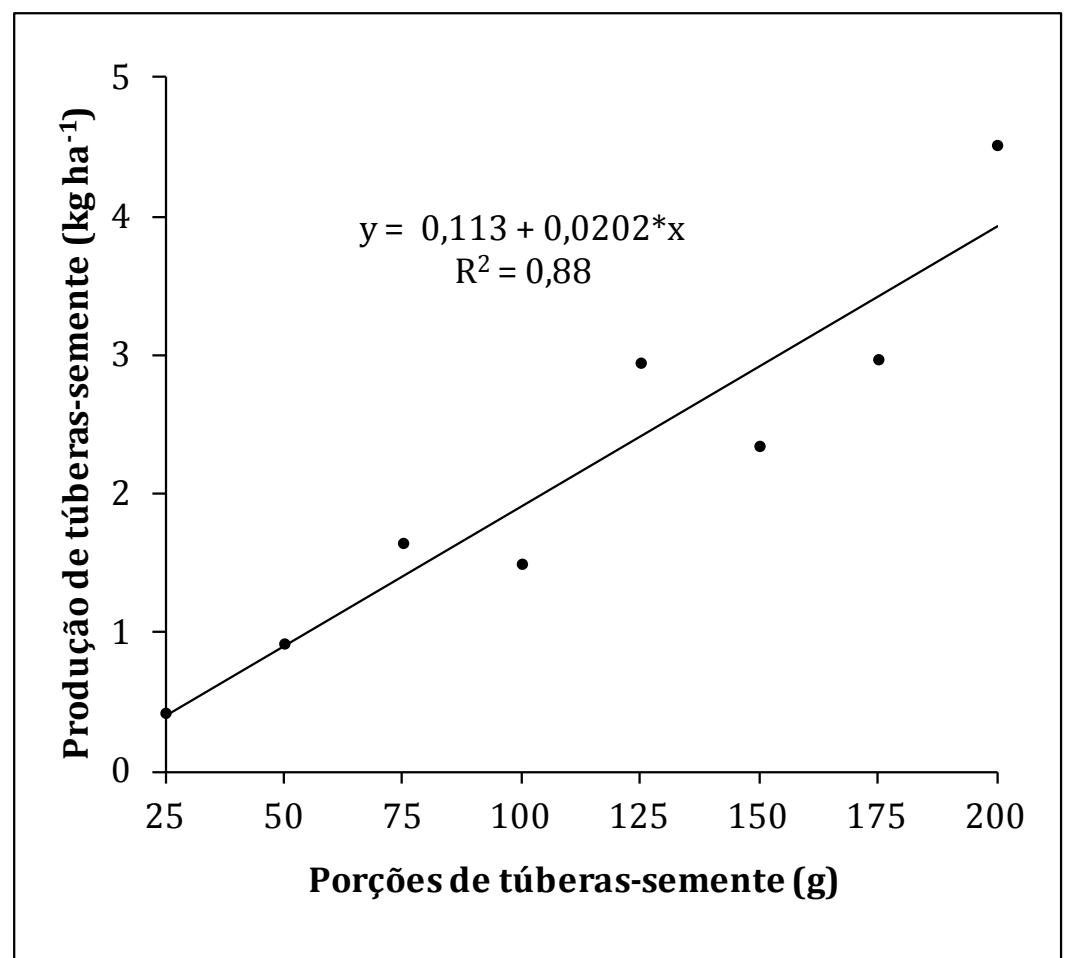

Figura 2. Produção de túberas-semente de inhame obtida por meio de plantio adensado de pedaços de túberas-semente, em $2,00 \mathrm{~m}^{2}$ (yam seeds production obtained by adensed planting of tubers-seed portions). Areia, UFPB, 2009.

vidade do estado da Paraíba, definida por Santos (1996) em 10 t ha $^{-1}$. Esse fato pode indicar que o plantio de inhame com uso de túberas-semente obtidas pelo processo de plantio adensado pode ser uma alternativa viável para o cultivo de inhame. A túbera-semente ideal para plantio do inhame, segundo Santos et al. 


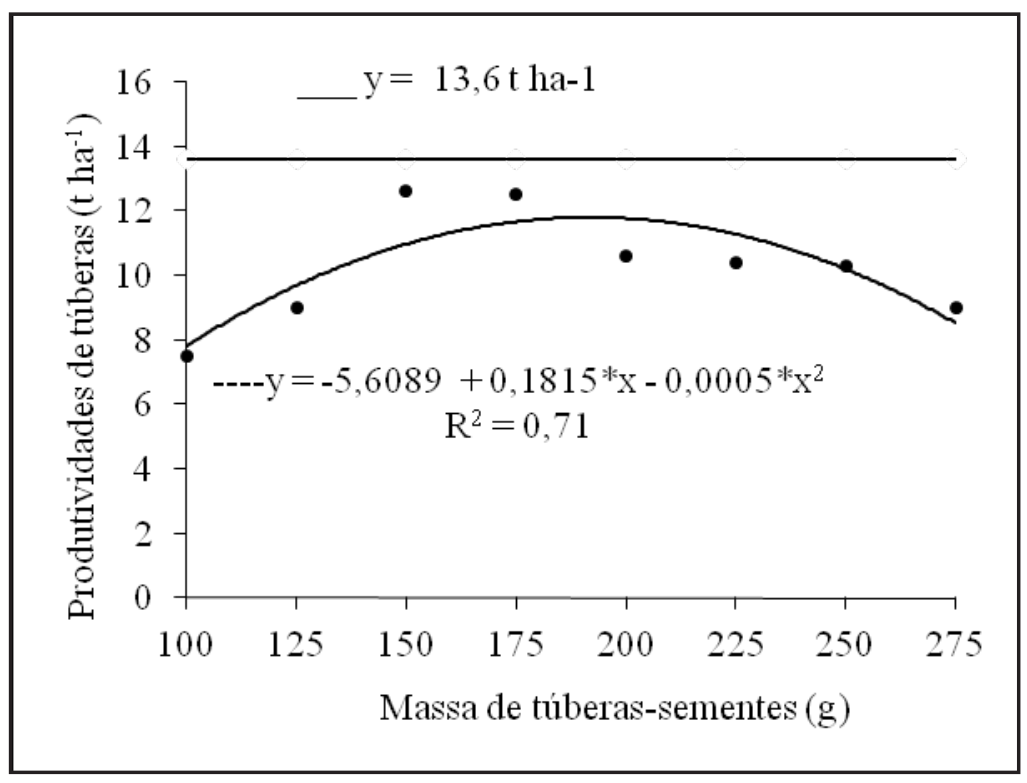

Figura 3. Produtividades total (-) e comercial (---) de túberas com o uso de peso de túberassemente obtidas pelo sistema de plantio adensado. (total and marketable productivity of tubers using seeds obtained by the adensed planting system). Areia, UFPB, 2009.

(2007b) deve apresentar peso médio de $200 \mathrm{~g}$, o que representa uma necessidade de $3.000 \mathrm{~kg} \mathrm{ha}^{-1}$, correspondendo a $40 \%$ do custo para implantação da cultura. Portanto, a recomendação do uso da túbera-semente com peso médio de 181 g representa uma economia de $34 \%$ na sua aquisição.

\section{AGRADECIMENTOS}

$\mathrm{O}$ autor Ademar $\mathrm{P}$ de Oliveira agradece ao $\mathrm{CNPq}$ pela bolsa de produtividade em pesquisa; os autores Damiana F da Silva, Arnaldo NP de Oliveira e Natalia $\mathrm{V}$ da Silva agradecem ao $\mathrm{CNPq}$ pela bolsa de iniciação científica.

\section{REFERÊNCIAS}

BRASIL. Ministério da Agricultura. 1972. Levantamento exploratório, reconhecimento de solos do Estado da Paraíba. Rio de Janeiro: MA/CONTAP/USAIO/SUDENE, 670 p. (Boletim técnico, 15).

OLIVEIRA AP. 2002. Nutrição e época de colheita do inhame (Dioscorea sp) e seus reflexos na produção e qualidade de rizóforos. In: SIMPÓSIO NACIONAL SOBRE AS CULTURAS DE INHAME E TARO, 2. 2002. João Pessoa, PB. Anais... João Pessoa, PB: EMEPA-PB. 2: p.83-98.

OLIVEIRA AP; FREITAS NETO PA; SANTO, ES. 2002. Qualidade do cará-da-costa em função de épocas de colheita e da adubação orgânica. Horticultura Brasileira 20: 115-118. OLIVEIRAAP; BARBOSA LJN; PEREIRA WE; SILVA JEL; OLIVEIRAANP. 2007. Produção de rizóforos comerciais de inhame em função de doses de nitrogênio. Horticultura Brasileira 25: 79-82.

SAEG. 2000. Sistema para análise estatística, versão 8.0. Viçosa-MG: Fundação Artur Bernardes, 2000.

SANTOS ES. 1996. Inhame (Dioscorea spp.): aspectos básicos da cultura. João Pessoa: EMEPA-PB, SEBRAE. 158 p.

SANTOS ES. 1998. Contribuição tecnológica para a cultura do inhame no estado da Paraíba. João Pessoa, PB: EMEPA-PB (Documentos, 23).

SANTOS ES. 2002. Manejo sustentável da cultura do inhame (Dioscorea sp.) no nordeste do Brasil. In: SIMPÓSIO NACIONAL SOBRE AS CULTURAS DE INHAME E TARO, 2. 2002. João Pessoa, PB. Anais... João Pessoa, PB: EMEPA-PB.1: 181-196.

SANTOS ES. 2006. Inhame: produção e preservação ambiental. João Pessoa: EMEPAPB. (Boletim informativo).

SANTOS ES; MACÊDO LS. 2002. Tendências e perspectiva da cultura do inhame (Dioscorea sp) no nordeste do Brasil. In: SIMPÓSIO NACIONAL SOBRE AS CULTURAS DE INHAME E TARO, 2. Anais... João Pessoa: EMEPA-PB. 1: 19-32.

SANTOS ES; CASÉ FILHO J; LACERDA JT; CARVALHO RA. 2007a. INHAME (Dioscorea SP.) tecnologia de produção e preservação ambiental. Tecnologia \& Ciência Agropecuária 1: p.31-36.

SANTOS ES; FONTINÉLLI ISC; LACERDA JT; MATIAS EC; BARBOSA MM. 2007b. Sistema alternativo de produção de sementes de inhame (Dioscorea sp.). Tecnologia e Ciência Agropecuária 1: 19-24.

SILVA DA. 2002. Novas opções tecnológicas para o cultivo do inhame (Dioscorea $\mathrm{sp}$ ) no nordeste do Brasil. In: SIMPÓSIO NACIONAL SOBRE AS CULTURAS DE INHAME E TARO, 2. 2002. João Pessoa. Anais... João Pessoa: EMEPA-PB. 1: 80-81.

SILVA DF. 2009. Tecnologia alternativa para produção de sementes do inhame e seus efeitos no rendimento de túberas. Areia: CCA-UFPB 23p. (Monografia graduação). 